Brit. J. vener. Dis. (1961), 37, 120.

\title{
GONORRHOEA AND ITS CONTROL IN FINLAND*
}

BY

\author{
A. S. HÄRÖ
}

Helsinki

According to the generally accepted view the infectious diseases are now under control and are losing their significance provided that the agent and the way of transmission are known and that treatment is effective, convenient, and safe. Contrary to this view, the new therapeutic methods have not solved the problem of venereal disease, and study of the epidemiology of gonorrhoea has again become of practical importance.

The Finnish venereal disease statistics have been based since 1953 on individual case reports, giving information of the disease and of the patient's age, occupation, and other data. The reports are collected and analysed by the State Medical Board. The reports and expenses of each approved doctor being controlled by the central authority, the reporting is quite reliable.

\section{Trends in Gonorrhoea Statistics}

Number of Cases and Sex Ratio.- The statistical picture clearly shows that since 1951 no real progress has been made, though the situation is better than before the Second World War. The yearly number of cases varies between $4,500-6,000$, the lowest number being 4,474 cases in 1958 . During 1959 the number rose by about 16 per cent. to 5,190 . During the years 1938-1956 the sex ratio varied between $1: 2 \cdot 5$ and $1: 4 \cdot 5$, and in 1957 and 1958 it has approached the pre-war level. The morbidity rate in women as compared with that in men was $1: 4$ in 1958 (Fig. 1; Table I).

Age and Marital Status.-In analysing the statistics by age, attention should be paid to the marital status of the patients. For unmarried persons, both male and female, the risk of infection is greatest at a

* Presented at the European Symposium of the I.U.V.D.T. at Cracow, Poland, in September, 1960. relatively late age, i.e. at about 30 years for men and about 25 years for women. In married persons the morbidity is less in the older age groups (Fig. 2; Table I).

TABLE I

CASES OF GONORRHOEA (PER 1,000 POPULATION) IN FINLAND, BY AGE AND SEX, 1953, 1957, AND 1958

\begin{tabular}{c|c|c|c|c|c|c}
\hline \multirow{2}{*}{$\begin{array}{c}\text { Age Group } \\
\text { (yrs) }\end{array}$} & \multicolumn{3}{|c|}{ Men } & \multicolumn{3}{c}{ Women } \\
\cline { 2 - 6 } & 1953 & 1957 & 1958 & 1953 & 1957 & 1958 \\
\hline & & & & & & \\
$20-19$ & 2.1 & 2.3 & 2.0 & 0.8 & 0.9 & 0.8 \\
$25-29$ & 7.7 & 6.9 & 6.9 & 2.3 & 1.7 & 1.8 \\
$30-34$ & 6.8 & 6.2 & 5.5 & 1.6 & 1.4 & 1.4 \\
$35-39$ & 4.5 & 3.8 & & 1.4 & 0.8 & \\
$40-44$ & 3.0 & 2.2 & & 0.9 & 0.5 & \\
$45-49$ & 1.7 & 1.4 & 2.0 & 0.5 & 0.4 & 0.5 \\
$50-54$ & 0.9 & 0.7 & 0.5 & 0.4 & 0.3 & 0.2 \\
\hline All Ages & 0.8 & 0.5 & 0.5 & 0.3 & 0.2 & 0.2 \\
\hline
\end{tabular}

The Teenager Problem.-To obtain a complete view of the age groups of the patients, it is necessary to review the trend during a longer period. For this reason the records of gonorrhoea of the city of Hensinki are most important. Figs 3 and 4 (overleaf) show the relative contribution of each age group as a percentage of the total number of cases notified each year. To preclude the effect of changes in the age structure of the population, the number of cases notified yearly in each age group has been standardized to the mean population at 1950 . The relative number of young male patients is increasing and the percentage has never been higher than it is at present.

In women, higher rates were seen during the period of economic depression and during wartime, but since 1950 the proportion of women patients under 20 years has nearly tripled. During the last 2 years, however, this trend is no longer so marked, but the share of women over 30 years has progressively increased and a slightly similar trend in men may also be observed. 


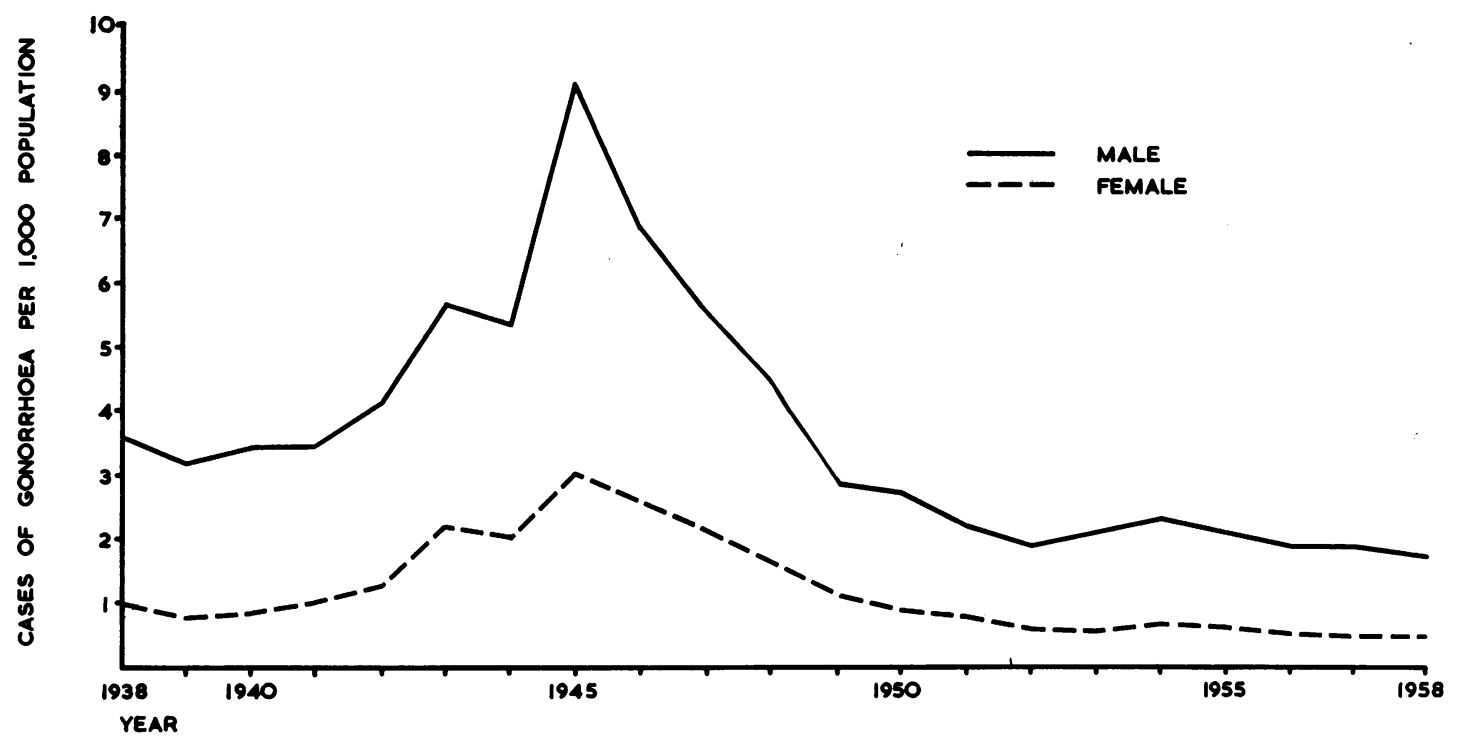

Fig. 1.-Incidence of gonorrhoea 1938-58, by sex.
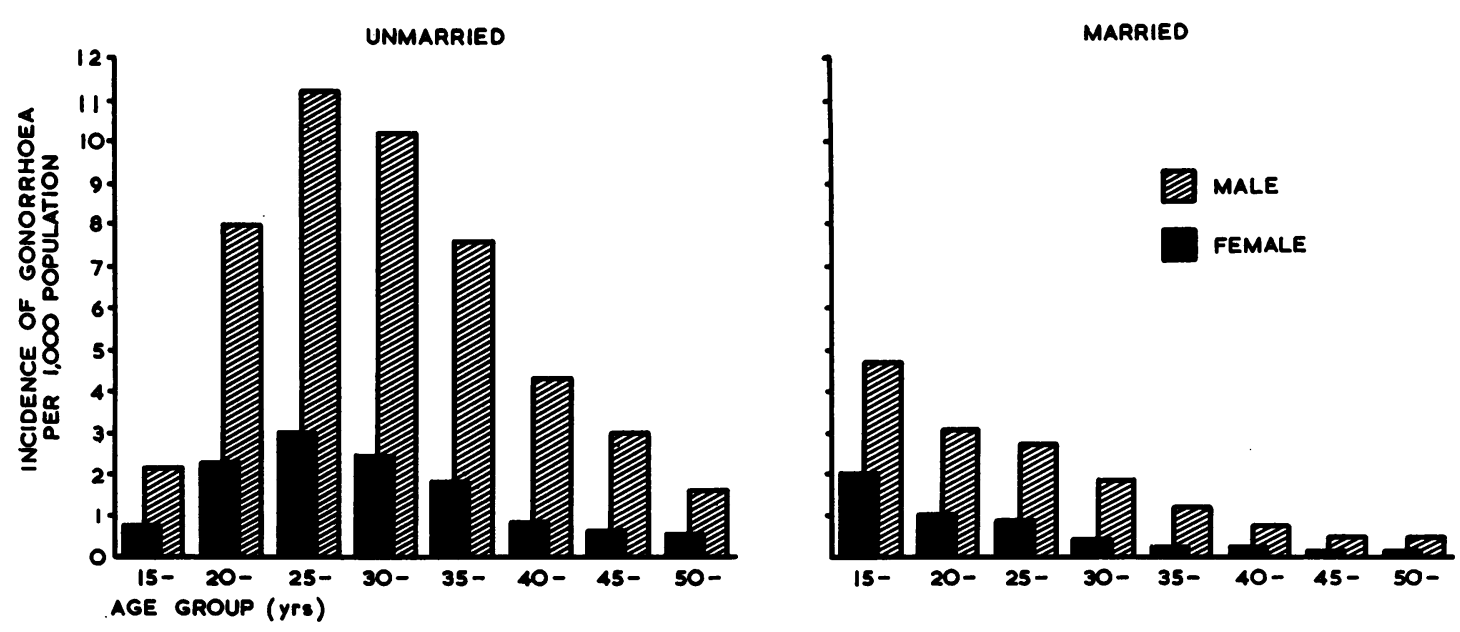

FIG. 2.-Incidence of gonorrhoea by age, sex, and marital status.

Time and Place of Infection.-There is an obvious connexion between venereal disease and holidays and other free time. In Finland the period of annual holidays is practically limited from 15 June to 15 August, and during this time the number of cases increases rapidly, but in all other months they are slowly decreasing. We feel that the fluctuation is a direct result of travel and other holiday amusements, and furthermore the infection is acquired on Saturdays and Sundays more often than on other days.

The incidence of gonorrhoea is relatively higher in the towns, especially in the bigger towns which are also seaports (Helsinki, Turku). In the fight against 


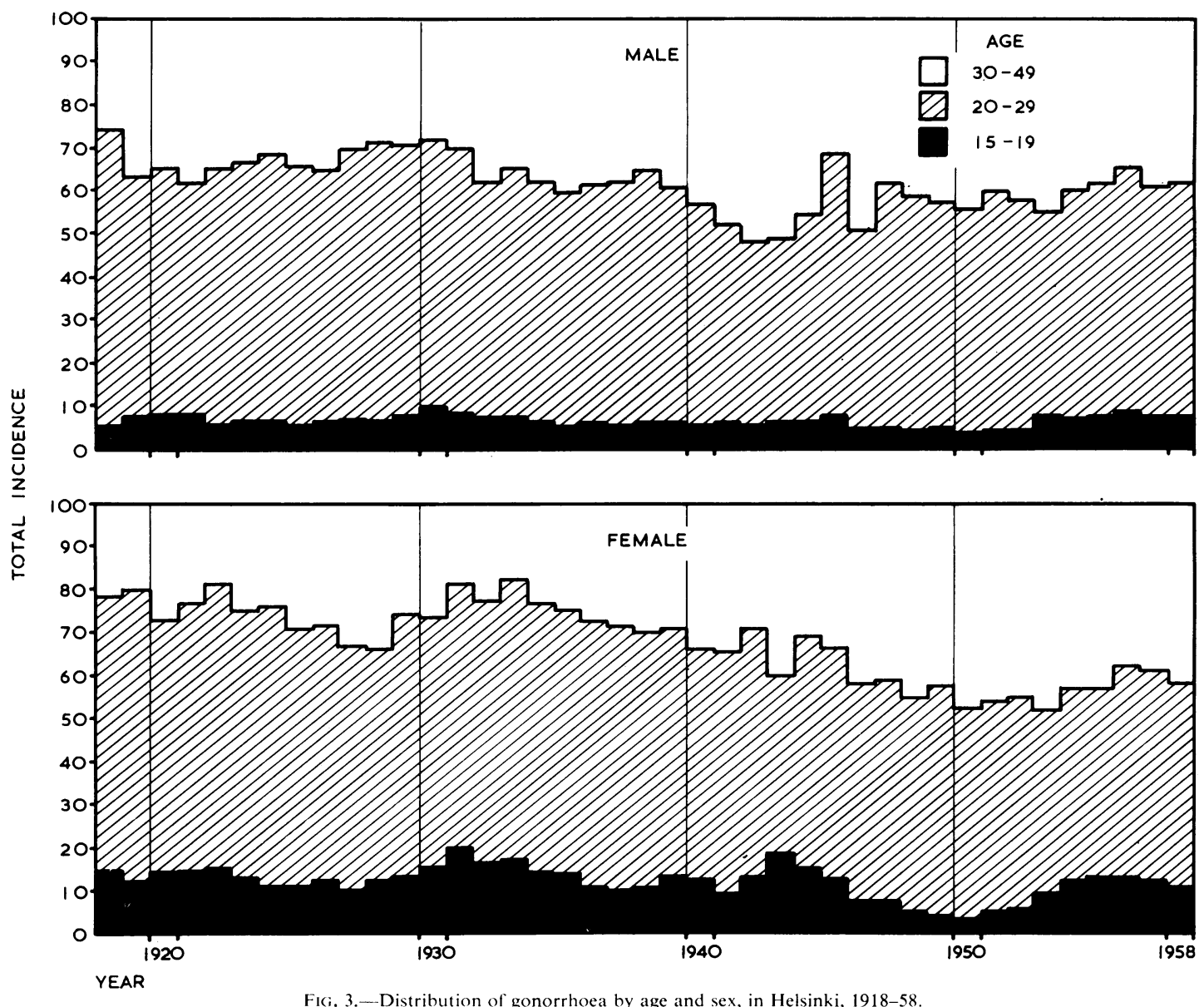

gonorrhoea, rural districts and small towns are insignificant and the large towns and cities play a decisive part in the problem (Table II).

58 per cent. of cases originated from the two biggest seaports, about 7 per cent. were sailors who acquired the infection abroad, mostly from the Baltic ports. If the infection is acquired from a port situated more than 6 to 7 days sailing from Finland it has usually been treated on board ship or in foreign ports.

TABLE II

CASES OF GONORRHOEA REPORTED IN FINLAND BY PLACE OF TREATMENT, 1953-58

\begin{tabular}{|c|c|c|c|c|c|c|c|c|c|c|c|c|}
\hline \multirow{2}{*}{\multicolumn{7}{|c|}{ Place of Treatment }} & \multicolumn{3}{|c|}{ Total Cases, 1953-1958 } & \multicolumn{3}{|c|}{ Yearly Rate per 1.000 Population } \\
\hline & & & & & & & \multirow{2}{*}{$\begin{array}{c}\text { Males } \\
10.312 \\
2.921 \\
3.053 \\
1,529 \\
1.471 \\
1,467 \\
2.396\end{array}$} & \multirow{2}{*}{$\begin{array}{c}\text { Females } \\
3,629 \\
745 \\
825 \\
277 \\
453 \\
443 \\
731\end{array}$} & \multirow{2}{*}{$\begin{array}{r}\text { Total } \\
13,941 \\
3,666 \\
3,878 \\
1.806 \\
1.924 \\
1,910 \\
3,127\end{array}$} & \multirow{2}{*}{$\begin{array}{c}\text { Males } \\
9 \cdot 8 \\
10 \cdot 0 \\
3 \cdot 8 \\
5 \cdot 2 \\
2 \cdot 2 \\
1 \cdot 8 \\
0 \cdot 3\end{array}$} & \multirow{2}{*}{$\begin{array}{c}\text { Females } \\
2.7 \\
2.1 \\
0.9 \\
0.8 \\
0.6 \\
0.5 \\
0.1\end{array}$} & \multirow{2}{*}{$\begin{array}{c}\text { Tota } \\
5 \cdot 7 \\
5 \cdot 6 \\
2 \cdot 2 \\
2 \cdot 8 \\
1 \cdot 3 \\
1 \cdot 1 \\
0 \cdot 2\end{array}$} \\
\hline $\begin{array}{l}\text { Helsinki ... } \\
\text { Turku } \\
\text { Other Smail Por } \\
\text { Tampere (Indust } \\
\text { Other Inland To } \\
\text { Market Towns } \\
\text { Rural Districts }\end{array}$ & $\begin{array}{l}\ldots \\
\ldots \\
\text { ts } \\
\text { trial T } \\
\text { wwns } \\
\ldots \\
\ldots\end{array}$ & $\begin{array}{c}\ldots \\
\ldots \\
\ldots \\
\text { own } \\
\cdots \\
\cdots \\
\cdots \\
\end{array}$ & $\begin{array}{l}\ldots \\
\cdots \\
\cdots \\
\cdots \\
\cdots \\
\cdots \\
\cdots\end{array}$ & $\begin{array}{l}\cdots \\
\cdots \\
\cdots \\
\cdots \\
\cdots \\
\cdots \\
\cdots\end{array}$ & $\begin{array}{l}\cdots \\
\cdots \\
\cdots \\
\cdots \\
\cdots \\
\cdots \\
\end{array}$ & $\begin{array}{l}\cdots \\
\cdots \\
\cdots \\
\cdots \\
\cdots \\
\cdots \\
\cdots\end{array}$ & & & & & & \\
\hline Whole Country & & $\ldots$ & $\ldots$ & $\ldots$ & $\ldots$ & $\ldots$ & 23,149 & 7,103 & 30,252 & 1.9 & 0.6 & $1 \cdot 2$ \\
\hline
\end{tabular}



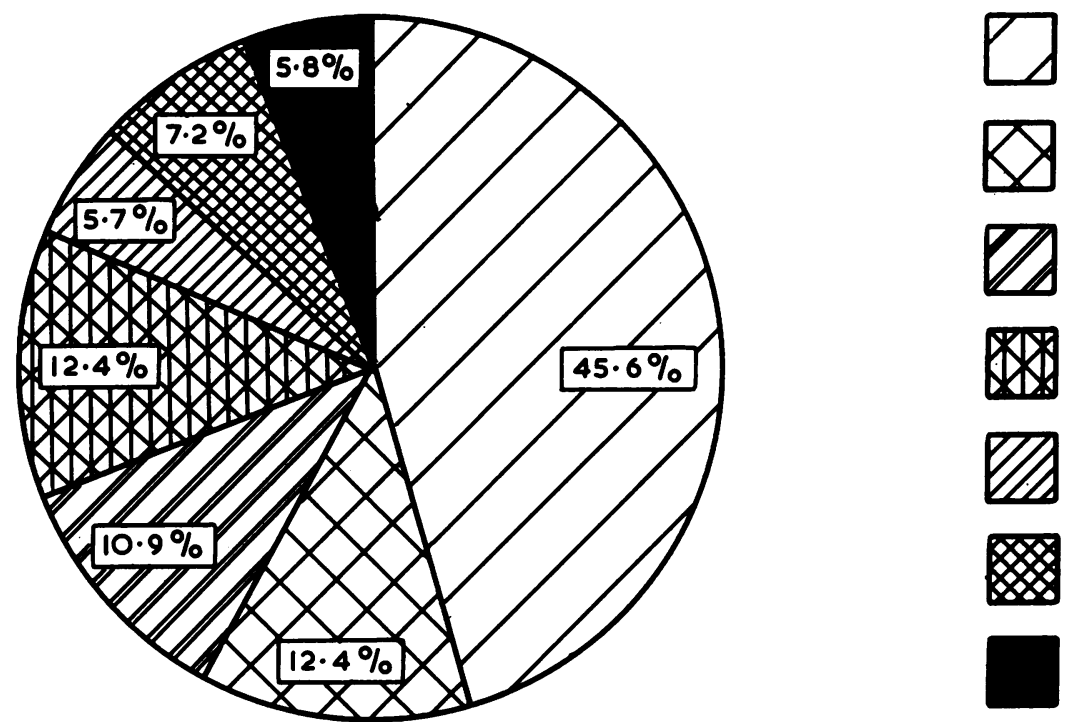

HELSINKI

TURKU

OTHER PORTS

OTHER INLAND TOWNS AND MARKET TOWNS

TAMPERE

FOREIGN COUNTRIES

RURAL DISTRICTS

Fig. 4.-Distribution of gonorrhoea by area.

Sources of Infection.-Consorts met in restaurants continue to be the most usual sources of infection, and the contribution of street prostitution seems to be decreasing. The typical habits of different age groups affect the sources of infection (Fig. 5). Dance halls are not important in older age groups, but restaurants are of growing importance until the age of 35-40 years. It is astonishing that temporary relationships beginning on the street and leading to venereal disease are as common in older as in younger men and that there are no marked differences in this respect between married and unmarried men. Impulse and heedlessness have evidently the greatest share in the temporary relations, and in this respect, age and family circumstances are not so significant as one would expect.

\section{Prevention and Treatment}

In Finland the treatment and control of venereal disease is based upon special legislation closely corresponding to that in the other northern countries:

Treatment is obligatory but free;

Compulsory power is vested in the health authority;

Case reporting for statistical and administrative purposes.

Each local authority must employ a whole- or part-time venereologist whose expenses are paid by the state.

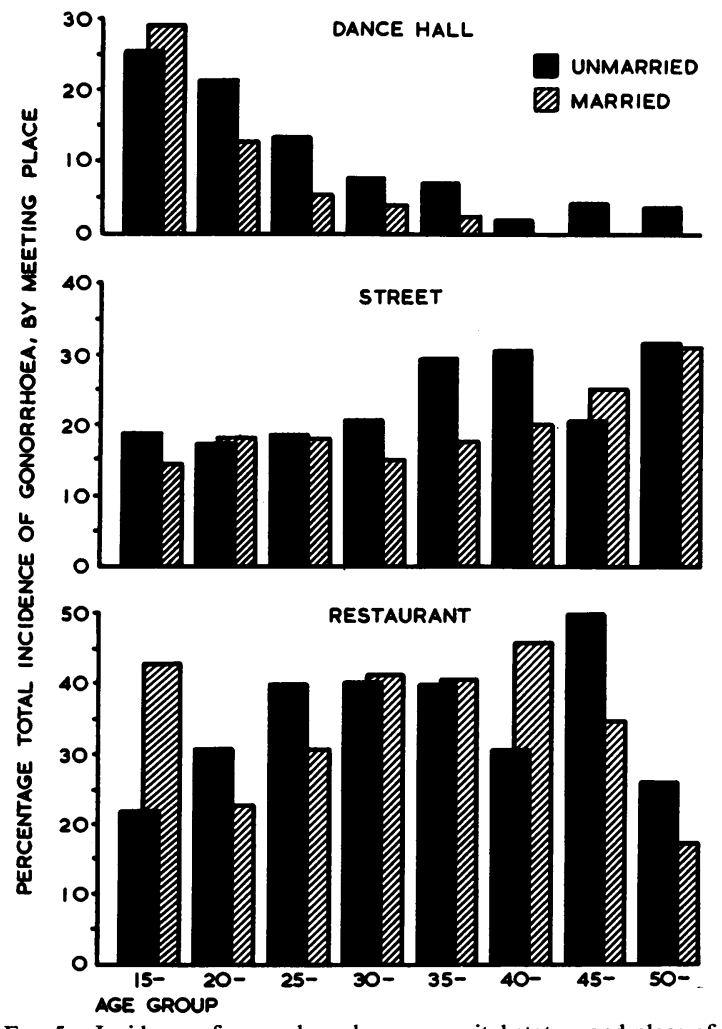

FIG. 5.-Incidence of gonorrhoea by age, marital status, and place of infection. 
The interviewing of patients for contact-tracing is a known weakness in case-finding, as most physicians have little time for this work, and specially trained social workers have not yet been used for the tracing of contacts. Moreover, information about foreign contacts is usually very unreliable and of no practical value.

Diagnostic Services. - The clinical picture, according to the general opinion of specialists in venereology, urology, and gynaecology, is less severe than formerly and the number of complications is small. The period of incubation is the same as in the prepenicillin era but the time between infection and treatment tends to be very long, especially in women living in rural areas.

The difficulties of microscopic diagnosis are unchanged and errors are not rare. Interest in venereal disease is so limited that the bacteriological laboratories are unwilling to cultivate gonococci. Only two central laboratories give this kind of service. The most difficult question has been the transport medium, but recently the method of Stuart (1959) has been accepted and experience with its use is encouraging.

Resistance tests in vitro have been used on a limited scale, but no fixed opinion of the results and methods has been arrived at. In 180 specimens there were three strains totally streptomycin resistant in vitro, but no penicillin resistant ones, though there were some clinically resistant cases. Small differences in resistance in vitro have been noted.

We feel that the value of laboratory services should be stressed and internationally accepted technical procedures should be recommended for general use.

\section{Therapy}

Penicillin is still holding its central position but the dosage is continuously growing. Nowadays, $1 \cdot 2-1 \cdot 5$ million units is normal but some workers are recommending 1.8-2.0 million units in uncomplicated cases of gonorrhoea. Procaine penicillin in water is generally used and a preparation is selected which gives an evenly high blood titre for $\mathbf{2 4}$ hours. The same dosage has been used for men and women. Streptomycin is used on a limited scale in clinically resistant cases, and also in penicillin-sensitive persons, etc. The usual dose has been $1 \mathrm{~g}$. in 2 days. Other antibiotics are used only exceptionally.

\section{Prophylaxis}

Mechanical prophylactic methods have gained from the selling of condoms from automatic machines in dance halls, restaurants, etc. Policlinics or other centres of clinical prophylaxis do not exist in Finland; chemotherapeutic prophylaxis is not used and the general opinion of doctors is against it. The only method which can be listed under this heading is the precautionary treatment sometimes given if the microscopic examination is negative but the possibility of infection exists. This occasional treatment without diagnosis is not epidemiologically very dangerous, and it is used only when the patient is asocial and unco-operative and then mostly for asymptomatic women.

From the social point of view there are also possible means of preventing venereal diseases. Sociological and epidemiological studies reveal new aspects and we feel that in this respect some methods are old-fashioned and formal. Commonly accepted half-truths cannot be proved statistically, e.g. that this problem concerns mostly teenagers and may be solved with simple measures of health education. It is obvious that the risk of catching venereal disease is greater among older patients and most patients are so old that such "education" can have little effect on their way of living.

The temporary relationships leading to venereal disease show the same thoughtlessness in married and unmarried, young and old. It is very difficult to find effective methods for anti-venereal propaganda but we feel that the main point should be in the value of family life and home.

The reservoir of infection is another central question. Studies carried out in other countries as well as in Finland indicate that the role of prostitutes is overestimated. The role of "enthusiastic amateurs" is becoming more important, and such people gather in certain restaurants and dance halls, the owners of which are not actively against this kind of economically profitable reputation. The supervision of such places would be an effective preventive measure from the point of view of the whole community. There are many other points in which the fight against venereal disease is in the interest of the whole community, such as propaganda and measures to assist the wise and healthy use of leisure. The venereal diseases present a problem which cannot be solved exclusively by scientific medical methods.

\section{Summary}

The yearly morbidity rate for gonorrhoea showed no marked changes in Finland in the years 1951-58, but in 1959 a slight increase was noted. Travel and tourism are important factors in the spread of 
gonorrhoea, and about 7 per cent. of cases are brought in by sailors. Contacts are mostly picked up at holiday times or in restaurants in the towns, street prostitution being of less importance. Legal measures designed to prevent the spread of venereal disease and methods of examination and treatment are discussed.

\section{REFERENCE}

Stuart, R. D. (1959). Publ. Hlth Rep. (Wash.), 74, 431.
Contrôle de la gonorrhée en Finlande

\section{Résumé}

La morbidité annuelle pour la gonorrhée n'a guère changé en Finlande de 1951 à 1958, mais elle a légèrement augmenté en 1959. Les voyages et le tourisme sont des facteurs importants dans la propagation de la gonorrhée, et environ $7 \%$ des malades sont des marins. La maladie se transmet surtout par contact pendant les vacances ou dans les restaurants des villes, et la prostitution sur la voie publique joue en rôle moins important. L'auteur discute les mesures légales préventives et les méthodes d'examen et de traitement. 